Anales de Literatura Hispanoamericana

ISSN-e: 1988-2351

\title{
El caso de la princesa Pignatelli
}

Günther Schmigalle ${ }^{1}$

Resumen. En un artículo redactado en 1902, Rubén Darío se refiere a la escandalosa y trágica vida de Gaëtana Pignatelli di Cerchiara, princesa de origen napolitano, cantante de cabaret, ninfómana, prostituta de alto nivel, hermana de la célebre Emmanuela Potocka y oveja negra de su aristocrática familia. Su biografía, que tratamos de reconstruir aquí, constituye uno de los contenidos sumergidos menos conocidos de las crónicas de Rubén Darío, y permite al lector acceder a los lados obscuros de la Bella Época y del mundo finisecular.

Palabras clave: Rubén Darío; Gaëtana Pignatelli di Cerchiara; Emmanuela Potocka; Belle Époque; Vida mundana.

\section{[en] The case of Princess Pignatelli}

Abstract. In an article written in 1902, Rubén Darío refers to the scandalous and tragic life of Gaëtana Pignatelli di Cerchiara, princess of Neapolitan origins, cabaret singer, nymphomaniac, high-level prostitute, sister of the famous Emmanuela Potocka and black sheep of her family. Her life, which we attempt to reconstruct here, is, among the submerged themes of Rubén Darío's chronicles, one of the least known, and allows the reader to access the obscure sides of the "Belle Époque" in Paris and other European cities.

Keywords: Rubén Darío; Gaëtana Pignatelli di Cerchiara; Emmanuela Potocka; Belle Époque; Mundane Life.

Cómo citar: Schmigalle, G. (2021) El caso de la princesa Pignatelli, en Anales de Literatua Hispanoamericana 50, 117-123.

En las últimas páginas del libro Parisiana de Rubén Darío surge el nombre de la princesa Cerchiara Pignatelli, inscrito en un monumento en el cementerio de perros de Asnières, al cual visita Rubén Darío en su calidad de reportero del diario bonaerense La Nación. El poeta-cronista adivina que se trata de una "aristocrática dama" que tuvo "una vida de sufrimiento" (Darío, 1907: 258-259). ¿Qué sabía exactamente de ella? Durante los años 1883-1890 su nombre se citaba con frecuencia en la prensa europea y americana. Pero antes de la referencia en Parisiana, que es del año 1902, Darío no parece haberla mencionado.

Para hablar de Maria Gaëtana Pignatelli di Cerchiara, personaje hoy olvidado, y de la condesa Potocka, su siempre célebre hermana, hay que hablar primero de la madre de ambas. Rosa Capomazza (1825-1909), nacida en el seno de una familia de la nobleza de Nápoles, se casó el 2 de enero de 1850 con Fabrizio Pignatelli di Cerchiara (1828-1856), cuando ella tenía 25 años y el marido 23. La primera hija, Gaëtana, nació el 15 de noviembre del mismo año, y su madre la trató con indiferencia porque el evento perturbaba su vida mundana. En 1852, durante un segundo embarazo, Rosa fue sorprendida por su marido en una situación íntima con su tío, un señor ya mayor, el duque Capece Galeota della Regina (1799-1867). La mañana siguiente, Fabrizio fue encontrado muerto con un golpe en la cabeza, de manera que ya no pudo acusar públicamente a su esposa; se divulgó que se había matado cayéndose de su caballo. A los cuatro meses nació la hermana de Gaëtana, Emmanuela. Cuatro años después, Rosa, con un permiso especial del papa, se casó, con su amante, quien, nombrado ministro plenipotenciario de Nápoles en Rusia, se la llevó a San Petersburgo, donde ella mantenía a sus hijas encerradas para que nadie supiera de su existencia que pudo haber obstaculizado su vida galante. Cansada rápidamente de su segundo marido que le parecía enfermizo, amargado y siempre ocupado, Rosa tuvo como amante a Alejandro Gorchakov, ministro del exterior, "el único hombre que alguna vez ha amado" según las memorias de Gaëtana (cit. Leibenson: 32). Parece que el 
mismo zar Alejandro II contaba entre sus pretendientes y posiblemente entre sus amantes. En 1860, cuando Nápoles fue tomado por las tropas de Garibaldi y el Reino de las dos Sicilias fue anexado por Piemonte, el duque de Regina perdió su puesto. Dos años después se trasladó con su familia de Petersburgo a Roma, donde Rosa, en el ambiente de carnaval, recuperó toda su alegría y pronto causó un escándalo que obligó al papa a desterrarla de Italia por cinco años (Leibenson: 38). La familia se trasladó a Suiza donde Rosa pasó su tiempo orando y cultivando una relación íntima con la aya de las niñas, una irlandesa piadosa. Siguiendo los consejos de esta, Rosa se trasladó a París, donde inauguró en su apartamento de la avenida Montaigne un salón al que invitaba la crema de la capital francesa. En el $\mathrm{n}^{\circ} 2$ de la misma avenida, contiguo al apartamento de Rosa, vivía Miceslas Potocki (1799-1878), un magnate polaco expulsado de Polonia en 1861 por decreto del zar, con sus hijos Grégoire (1843-1871) y Nicolás (1845-1921). Estamos en 1865. La cercanía facilita el acercamiento, y Grégoire, que tiene 22 años, se enamora de Gaëtana, que tiene 15, mientras Nicolás, que tiene 20 años, se enamora de Emmanuela, que tiene 13. Sin embargo, Rosa, que tiene sus propias inquietudes y ambiciones, logra desviar el afecto que siente Grégoire por su hija, a su propia persona. En enero de 1867 Miceslas compra un "hotel particulier", o más bien un palacio suntuoso en la esquina de la avenida de Friedland con la rue Balzac (Leibenson: 69-70). En diciembre de 1867 muere el conde de Regina. En octubre de 1870, Rosa, con un nuevo amante de apellido North, sus dos hijas y Nicolás Potocki, el pretendiente de Emmanuela, huyen en un globo aerostático de la capital francesa asediada por el ejército prusiano y se trasladan a Londres, donde Nicolás y Emmanuela se casan. Grégoire, de quien Gaëtana sigue enamorada, muere en un accidente en Saint-Cloud, cuando trata de desactivar un obús. En 1871, la familia regresa de Londres a París, capital medio destruida por los trabajos de Haussmann, la guerra franco-prusiana y los eventos de la Comuna. En la mansión de la avenida de Friedland, Nicolás discute con Emmanuela, Rosa está furiosa porque el señor North la ha abandonado para casarse con otra, Miceslas teme ser envenenado, amenaza a Nicolás con desheredarlo porque no le han dado un nieto, y se busca una amante entre la servidumbre de la casa. Rosa Catana, una cortesana amante del difunto Grégoire, trata de apoderarse de la mansión por medio de un testamento falso. Para Gaëtana, la vida en la casa es un infierno ${ }^{2}$, y las escapadas de "la que tiene que llamar su madre" la indignan. Cuando Alfonso Capecelatro (1824-1912), un sacerdote de origen napolitano que es el nuevo amante de su madre, trata de seducirla también a ella, huye de París a Monte-Carlo, donde Dmitrievna Varvara Mergassova, la condesa Rimsky-Korsakow (1833-1878), le ha ofrecido su hospitalidad(Leibenson: 93-97). Esa breve fuga se saldará con otro fracaso emocional, cuando Gaëtana se enamora ingenuamente del príncipe Adolphe de Wrede, un jugador impenitente, ex oficial del ejército ruso y nieto del mariscal bávaro Carl Philipp von Wrede(Leibenson: 189-190) ${ }^{4}$.

Con la muerte de Miceslas, el 27 de noviembre de 1878, su fortuna, valorada en unos 80 millones de francos de la época ${ }^{5}$, por fin pasa a las manos de Nicolás, y éste permite a su esposa Emmanuela, durante los años 1880, presidir y dirigir uno de los salones más brillantes de París, donde artistas, músicos y escritores se codean con la aristocracia europea y con hombres políticos. Distanciada y pronto separada de su marido, admirada por el público cuando sale a dedicarse a sus compras compulsivas, pero despreciada en su propia casa, Emmanuela entretiene en magníficas recepciones a la crema y nata de París, divierte a los invitados con sus pleitos dramáticos con Marie $\operatorname{Kann}^{6}$ y humilla a los invitados cuando se enamoran de ella. Guy de Maupassant, Octave Mirbeau, Paul Bourget, Jean Lorrain, Jacques-Émile Blanche y Marcel Proust, la retratan en sus novelas, donde expresan su fascinación y exasperación con ella. Gaëtana (nunca invitada a las recepciones de su hermana) tiene menos suerte. En marzo de 1875 se rumorea que se va a casar pronto con el historiador Henry Houssaye, hijo del escritor Arsène Houssaye, amigo de Nicolás Potocki ${ }^{7}$, pero el proyecto fracasa ${ }^{8}$. Gaëtana se enamora de otro pretendiente, el oficial coracero Gaston Raymond, de quien habla ampliamente en sus memorias (cf. Leibenson: 168-171), pero tiene que conformarse con un esposo elegido

\footnotetext{
${ }^{2}$ Memorias de Gaëtana, cit. en Leibenson 90.

${ }^{3}$ Memorias de Gaëtana, cit. en Leibenson 92.

${ }^{4}$ Leibenson 189-190. Durante los últimos años del siglo, Wrede ocupó las páginas de los periódicos por haberse casado dos veces: en 1892, en París, con una bonita austríaca, la señorita Ludmille Maldaner, y nuevamente en 1893, en Suiza, con una riquísima dama argentina, la señora Carmen Dolores Josefa de Alvear, viuda de Benítez, lo cual provocó largas complicaciones jurídicas. Cf. Léon Prieur, "Chronique judiciaire", Le Soleil, 24 de junio de 1898 , pág. 2.

${ }^{5}$ El salario anual promedio de un obrero era de 800 francos (Leibenson 144).

${ }^{6}$ Marie Warschlawski (1861-1928).

${ }^{7}$ Le Figaro, 15 de febrero de 1875, pág. 1; "Characteristically Frenchy. Arsène Houssaye's Paris Correspondence of the New York Tribune", Cincinnati Daily Gazette, 15 de marzo de 1875, pág. 5.

${ }^{8}$ El 28 de octubre del año, Houssaye se casa en la iglesia Saint-Philippe-du-Roule con Eugénie Ritter, de Nevada City (California).
} 
por la familia, el conde Louis Piper, nativo de Mecklemburgo. Éste tiene dinero, pero al poco tiempo se enamora de una soubrette y desaparece sin dejar huellas, dejando a la princesa sola, sin recursos y con dos hijos 9 . En junio de 1878 Gaëtana, después de varios intentos, logra el divorcio definitivo ante el tribunal civil de la ciudad de Hamburgo y se instala en un apartamento amoblado en la rue Chalgrin, con su hijo Aristide (la hija estaba en una pensión en Turín) y con la única empleada que le quedaba (Leibenson: 169). La familia (o sea, su madre, su hermana y su cuñado) culpan a Gaëtana del divorcio, y para castigarla le cortan los víveres $^{10}$. Se decide entonces a iniciar una carrera como cantante. Su debut, el 16 de octubre de 1883 en el café-concierto-teatro La Scala (13, boulevard de Strasbourg), causa mucho revuelo. Las 1400 plazas de la Scala se llenaron hasta la última y el señor Allemand ganó 25,000 francos en tres meses. Lamentablemente, la princesa no logra ganarse ni al público, ni a los periodistas. Según Jules Claretie, la apariencia física de Gaëtana fue impresionante, pero su canto no estaba a la altura de las expectativas ${ }^{11}$. A un reportero británico la princesa confiesa:

Mi cuñado, el conde Nicolás Potocki, canceló la pensión de mil francos mensuales que me pagaba mi familia desde que vivo separada de mi marido. Además quiso quitarme a mis dos hijos para hacerlos educar por religiosos y alienarme su afecto. En sus ojos soy solo una aventurera. Hace ocho días mi hermana, cuando me encontró casualmente en el trayecto de su coche, apartó la mirada con desprecio ${ }^{12}$. ¿Qué hacer? ¡Hay que buscar cómo vivir! Antes de tomar la decisión que usted sabe, traté de interesar al señor Gounod ${ }^{13}$ en mi suerte, pero en vano: todas sus ideas giran alrededor de la religión. Me dirigí entonces a un diputado radical, pero mi título de princesa lo asustó. En fin, no sabiendo ya a qué santo encomendarme, visité al director de la Scala ${ }^{14}$, que aceptó pagarme los sueldos mensuales que necesito... ¿Por qué el público, cuando conocerá mi triste historia, no me permitirá ganarme la vida con el único medio que me es accesible? Ya he cantado en conciertos de caridad. Que no se me impida ahora cantar para el beneficio de mis hijos... ${ }^{15}$.

Otro periódico ${ }^{16}$, quizás con mala intención, declara que la familia pagaba (irregularmente) una pensión a la princesa para que no diera a luz la segunda edición de un libro que había publicado bajo un seudónimo ${ }^{17}$. El lunes 14 de enero de 1884, la princesa, lamentablemente afectada por un fuerte resfrío, inicia sus representaciones en el popular "Royal" Music Hall en Holborn (Londres), bajo la dirección de W. T. Purkiss, donde atrae grandes muchedumbres ${ }^{18}$. Una semana después, un periódico irlandés la describe siempre como "the crowning attraction at the Holborn Music Hall", pero lamenta que "her vocal powers are said to be below par" y que "she cannot be considered much of a success from an artistic point of view"

9 “The Princess Pignatelli”, The Era, 22 de diciembre de 1883, pág. 4. Los hijos fueron Aristide, nacido en 1877, y Henriette, nacida el 20 de noviembre de 1878. Parece que Aristide murió en 1906, a la edad de 29 años (Leibenson 147, 443).

${ }^{10}$ Parece que el Gaetana tuvo otro hijo, Amedeo Pignatelli de Cerchiara, nacido en París el $1^{\circ}$ de octubre de 1882 , quien se hizo comerciante en Braunschweig y se casó el 29 de julio de 1910, en Frankfurt am Main, con Klara Katharina Anna Zamecznik, nacida en Frankfurt el 20 de mayo de 1882, sin profesión, con domicilio en Frankfurt, Blücherstraße 9, hija del pastelero Eduard Karl Zamecznik y de su esposa, ambos difuntos. Su acta de matrimonio se encuentra en www.ancestry.com. Se ignora quién fue su padre.

${ }^{11}$ Jules Claretie, "La Vie à Paris“, Le Temps, 19 de octubre de 1883, pág. 3.

${ }^{12}$ En la avenida de las Acacias (Leibenson 175).

${ }^{13}$ El compositor Charles Gounod (1818-1893), sacerdote en su juventud, dedicado a la música religiosa en la última parte de su vida.

${ }^{14}$ El señor Marius Allemand y su esposa Sophie Allemand, originarios de Marsella, fueron los directores de los cafés cantantes Scala (n ${ }^{\circ} 13$, boulevard de Strasbourg) y Eldorado ( $\mathrm{n}^{\circ} 4$, boulevard de Strasbourg) y del teatro y music-hall Folies-Bergère ( $\mathrm{n}^{\circ} 52$, rue Richer).

${ }^{15}$ Le Petit Caporal, 19 de octobre de 1883, pág. 4. También en sus memorias (cf. Leibenson 169-171).

16 “Courrier des Théâtres”, L'Événement, 24 de octubre de 1883, pág. 3.

${ }^{17}$ Histoire de deux bouquets fanés, par Marie-Thérèse D*** (París: Amyot 1875) es una narración autobiográfica y una novela en clave. Los personajes que se pueden identificar con facilidad son la huérfana Jacqueline Olda = Gaetana; su prima Elfa Olda = su hermana Emmanuela; su tía Charlotte Olda, convertida en vizcondesa de Tilly = su madre Rosa Capomazza, convertida en codesa della Regina; el vizconde de Tilly = el duque Capece Galeota della Regina, padrastro de Gaetana. La patria de Jacqueline, un país caliente donde florece el naranjo, con una ciudad con vista al mar azul y una montaña que echa humo, se identifica también fácilmente. La muerte del padre, quien se fractura la cabeza en una piedra después de caerse de su caballo, es mencionada muy al inicio (pág. 3). Los "seis años en Suecia", donde las niñas, en invierno, sufren del frío espantoso, corresponden a cinco años en Rusia. No se ha identificado a Théophile K. ni a Gaston de M..., amantes traicioneros de Gaetana. El casamiento de Elfa con el barón Armand de Géry, 4 de octubre de 1870 en la iglesia Santa María de L..., "una pequeña ciudad en Calvados", parece una transfiguración del casamiento de Emmanuela con el conde Nicolas de Potocki, en Londres, el 5 de noviembre de 1870 . Potocki seguramente no se puso muy contento al verse retratado como "un novio muy feo y muy insignificante, de carácter pesado, maneras insolentes y un espíritu absolutamente inculto" (pág. 46). Los retratos satíricos de otros personajes, como de cierta "dama moscovita rica, fea, estúpida y malvada" (pág. 73), recuerdan, en su estilo, a Rabelais. En dos ocasiones se anuncia la preparación de un segundo volumen en el cual se contará entre otras cosas la muerte atroz del novio traicionero Théophile K. La Histoire... es un grito de corazón, muy espontáneo, escrito en tres semanas, una polémica contra el matrimonio burgués y un libro de combate a favor de la liberación de la mujer. Todavía no se le ha dado el lugar que merece en la literatura feminista de la época.

18 "The London Music Halls", The Era, 19 de enero de 1884, pág. 10; T. Johnson, "Correspondance Anglaise”, Le Figaro, 30 de enero de 1884 , pág. 3; Le Cri du Peuple, $1^{\circ}$ de febrero de 1884, pág. 4.

19 “Latest News", Freeman's Journal, 21 de enero de 1884, pág. 5. 
París, Gaëtana trabaja como camarera en Le Monarque, el bar en las Folies-Bergère que durante su actividad se convirtió en una mina de oro para su propietario ${ }^{20}$. Leibenson comenta que la frontera entre las camareras de café-concierto y las prostitutas era borrosa y que "se puede imaginar que Gaëtana ... no siempre podía resistir las tentaciones que se le ofrecían" (Leibenson: 174). Nicolás ofrece pagar todas sus deudas y además regalarle más de diez mil francos si aceptaba abandonar París inmediatamente, y Emmanuela le confiesa que se desquita con ella y que le ha dado por castigarla con su látigo de caballos. El conde estaba especialmente furioso porque sus amigos habían descubierto que tanto Gaëtana como Emmanuela figuraban en un reciente repertorio de las prostitutas de París, destinado al uso de los turistas británicos ${ }^{21}$. En la misma vena, un artículo de L'Écho de Paris compara a Gaëtana con un personaje literario, una noble española que se hace prostituta para vengarse de su marido ${ }^{22}$. Una demanda por difamación presentada por la princesa no tiene éxito y le hace perder las últimas simpatías en el mundillo periodístico ${ }^{23}$; en adelante, los cofrades de Edmond Deschaumes y de Aurélien Scholl la tratan sin miramientos, probablemente bajo la influencia de fuertes sumas que les paga el conde Potocki ${ }^{24}$. En noviembre de 1884, los periódicos informan que trabaja como cantante en el Orpheum, café concierto-circo-teatro-feria de Viena, donde el público la aplaude por "cantar falso en tres idiomas" 25 . Otros afirman que su plan es abandonar la carrera de cantante y hacerse jinete de circo o domadora de leones ${ }^{26}$ y que concluyó un contrato con el circo Suhr, el cual incumplió después de recibir un adelanto de 660 florines $^{27}$. En febrero de 1885 ofrece un gran concierto en un local de Berlín, el "Wintergarten" 28 , en septiembre del mismo año, se nota su presencia en la Academy of Music, un café-concierto-tugurio "infecto" de la capital alemana ${ }^{29}$, y en octubre, en el Sedan, otro local "infecto" de la misma ciudad ${ }^{30}$. En enero de 1886, siempre según los periódicos, la princesa se encuentra otra vez en Viena, donde fracasa nuevamente como cantante, trabaja en un bar sirviendo champán ${ }^{31}$, y finalmente la aristocracia local recoge suficiente dinero para ofrecerle una renta y colocar a su hijo en una casa de educación con jóvenes de la aristocracia austríaca ${ }^{32}$. El mismo año, un periódico informa que Marie Gaëtana se casará con un señor Bistritzky, propietario del Eldorado de Viena ${ }^{33}$, un conjunto amplio de jardines de cerveza y otros locales de vida nocturna, pero, como su marido está todavía desaparecido, se dirigirá al papa para obtener una dispensa ${ }^{34}$. Pocos meses después, la princesa da a conocer que su noviazgo con el señor Johann Bistritzky fue serio por su parte, pero que de parte de él se trataba solamente de una broma y de una réclame para su establecimiento:

¡Es una desgracia para una mujer como yo de haber sido ridiculizada de esa manera! Lo siento, pero me apresuro en darlo a conocer al público vienés, que amo tanto, y a mi querida ciudad de Viena, que es ahora mi patria ${ }^{35}$.

En mayo de 1887 hace un viaje a Venecia, donde causa revuelo cantando en el barco "Cattaro"36. Este año trabaja como "Blumenmädchen" (vendedora de flores) en La Maison Rouge, un café nocturno de Viena ${ }^{37}$, pero se queja en una carta dirigida a los periódicos que los caballeros que le compran muchas veces ni se

${ }^{20}$ Pierre Véron, “Courrier de Paris”, Le Monde Illustré, 14 de junio de 1884, pág. 370; memorias de Gaëtana, cit. en Leibenson 174.

${ }^{21}$ Gaetana se describe en la guia como "a little, short-sighted, dark lady, very stout and very excitable", y su hermana Emmanuela como "a furious disciple of Sappho" (Anónimo, The Pretty Women of Paris, págs. 153-154).

${ }^{22}$ Edmond Deschaumes, "Paris-Gazette", L'Écho de Paris, 11 juin 1884, pág. 1. Se refiere a "La vengeance d'une femme", en Barbey d'Aurevilly 305-354.

${ }^{23}$ Journal de Débats, 11 août 1884, pág. 3.

24 "El conde Potocki había comprado la prensa parisiense con cincuenta mil francos para volverme inofensiva, inmediatamente y para siempre" (memorias de Pignatelli, cit. en Leibenson 174).

${ }^{25}$ Walter Vogt, "Courrier de Vienne", Le Figaro, 5 de noviembre de 1884, pág. 4.

${ }^{26}$ Le Voltaire, 29 novembre 1884 , pág. 4.

${ }^{27}$ Le Matin, 5 de enero de 1885, pág. 3.

${ }^{28}$ L'Écho de Paris, 6 febrero de 1885 , pág. 1

${ }^{29}$ Paris, 29 septiembre de 1885, pág. 2.

${ }^{30}$ Gil Blas, 18 de octubre de 1885 , pág. 1.

31 “Occasional Notes", Pall Mall Gazette, 1 de julio de 1886, pág. 4.

${ }^{32}$ Le Voltaire, 25 de enero de 1886, pág. 1.

${ }^{33}$ El "Eldorado", remodelado en 1899 bajo el nombre "Wiener Ballhaus", figuraba en la lista de los locales cuya visita estaba prohibida a los oficiales del ejército austríaco, debido a su mala reputación (Karl Kraus, Die Fackel, n 61, diciembre de 1900, pág. 13).

${ }^{34}$ Le Figaro, 16 de junio de 1886, pág. 6.

${ }^{35}$ Carta fechada el 27 de octubre de 1886, Die Presse (Viena), 28 de octubre de 1886, pág. 14; Le Figaro, 31 de octubre de 1886, pág. 3 . Cf. Snob, "Les Potins de Paris", Le Rire, 2 de febrero de 1906.

${ }^{36}$ Die Presse, 5 de mayo de 1887 , pág. 15.

37 "Feuilleton - Dies und das", Wiener Sonn- und Montagszeitung, 25 de julio de 1887, pág. 1. 
quitan el sombrero ${ }^{38}$. A partir de 1887 , tanto en los periódicos franceses como austríacos, el nombre de la princesa se ha convertido en una referencia histórico-burlesca: todos creen saber quién es ella y se ríen de ella. En 1888 y 1889 trabaja en el Kursaal, un local de baile muy conocido de Berlín, y es objeto de una pantomima satírica en el American Theater ${ }^{39}$. Sus memorias, publicadas también en Berlín, tienen bastante éxito en Alemania y son reseñadas con mucha simpatía en Inglaterra ${ }^{40}$, pero pasan completamente desapercibidas en Francia, y aún la edición alemana ha desaparecido completamente del mercado de libros viejos $^{41}$. En 1892 visita Viena durante un viaje de Escandinavia a Italia y ofrece unas charlas en el Café Hamburg, en la Heumühlgasse $14^{42}$. En 1894 se informa que la princesa desde hace tiempo canta en un local de Ofen (Buda) y que vive con sus hijos en la miseria; pero, según la Revista Internacional de Artistas de Hungría, un tío se acordaba de ella en su lecho de muerte, y acordó con sus hijos utilizar una parte de su fortuna para dejarle una renta, a condición de que abandonara para siempre el mundo del teatro, condición que ella aceptó ${ }^{33}$. En 1897 se rumorea que la princesa ha muerto en El Salvador, pero después sale que no se trataba de ella sino de su colega la princesa rusa y violinista Dolgorucki, de origen español. Según algunas noticias Dolgorucki fue envenenada por su empresario francés Edmond Moreau, según otras murió de la fiebre amarilla. María Gaëtana había colaborado con ella en varias ocasiones ${ }^{44}$. En 1895 un periódico americano relata que la princesa se ha retirado de la vida pública después de casarse con el propietario de un jardín de cerveza (¿ya no Bistritzky, sino otro?), quien, al morir, le dejó una aceptable herencia y tres hijos (¿?) a cuya educación dedica todo su tiempo, en una pequeña ciudad a cien millas de Viena ${ }^{45}$.

Sin embargo, parece que la princesa no se quedó viviendo en la campiña austríaca, sino que volvió a Francia. De su nueva vida en París en estos años no se sabe nada. ¿Seguirá la "canción de su vida", como la llama Walter Benjamin, la de esos seres humanos "que no conocen ninguna evolución, al no ser que se quiera llamar evolución eso de que caen de un desastre a otro, como un cuerpo que cayendo no omite ninguna de los peldaños de piedra de una escalera" (Benjamin: 220-221)? El 15 de noviembre de 1909, Gaëtana está presente, al lado de su hermana, en las obsequias de su madre, Rosa, duquesa de Regina, en la Iglesia Notre-Dame de Auteuil. Es la última vez que su nombre se menciona en la prensa francesa ${ }^{46}$. El 23 de noviembre de 1921, Gaëtana muere en un hospital de París (Leibenson: 476), completamente olvidada, según parece, ya que ningún periódico menciona su muerte.

El recuerdo más visible que dejó la princesa es un monumento que erigió en el cementerio de perros de Asnières, lo cual nos indica que en ese momento vivía en París y tenía suficientes medios para permitirse ese pequeño lujo. La inscripción en el monumento reza: A la memoria de mi querida Emma, del 12 de abril de 1889 al 2 de agosto de 1900, fiel compañera y única amiga de mi vida errante y desolada. Ella me salvó la vida en mayo de 1891. El cementerio de Asnières, inaugurado en 1899, fue el primero de ese tipo en Europa y América. Muchos de los curiosos que lo visitaron mencionan el monumento, que se encuentra en un lugar bastante destacado y se distingue por su tamaño y su estilo. Serge Basset observa y lee la inscripción, "bajo una bóveda de piedra que protege una galga esculpida sobre un cojín con las armas de la princesa de Cecchiara-Pignatelli", y la cita en su artículo ${ }^{47}$. Berthe Vercler la cita también ${ }^{48}$, y otro periodista que usa un seudónimo relata: "Aquí está, dice nuestro guía, la tumba de Emma, que salvó la vida de su dueña, la princesa de Cerchiara Pignatelli“449, como también un periodista austríaco anónimo: "Dos de estos monumentos se destacan especialmente, tanto por su ejecución original en piedra arenisca, como por su tamaño. ... Además, en el centro de la sección de los perros, se encuentra un monumento, por encima del

\footnotetext{
${ }^{38}$ Wiener Allgemeine Zeitung, 18 de julio de 1887, pág. 2.

${ }^{39}$ Die Presse, 13 de septiembre de 1888 , pág. 11.

40 "From Palace to Restaurant", Pall Mall Gazette, 8 de julio de 1889, pág. 3

${ }^{41}$ La única explicación es que alguien compró y destruyó todos los ejemplares disponibles. No es difícil adivinar quién fue. Ya en 1886, el conde Potocki mandó a recoger y destruir todos los ejemplares que circularon en París, de un Mémoire publicado por su primo, el conde Jean Zamoyski, sobre la solicitud de divorcio y anulación de matrimonio presentadas por su esposa, la señorita Louise Pélissier de Malakoff. Zamoyski fue heroinómano y muy violento; su esposa fue una histérica, en tratamiento con Charcot. El Mémoire fue incautado en Viena por orden de un tribunal, por ofensa a las buenas costumbres e incitación a la rebelión ("Un grand procès", Gil Blas, 15 de septiembre de 1886, pág. 1; "Zwei merkwürdige Druckschriften“, Die Presse, 2 de agosto de 1886, pág. 3; Leibenson 285, 328). La "incautación” en París no tuvo ninguna base legal, pero Potocki se habrá dado cuenta que los libros incómodos se pueden hacer desaparecer de esa manera.

${ }^{42}$ Neue Freie Presse, 17 de septiembre de 1892, pág. 12.

${ }^{43}$ Die Presse, 5 de diciembre de 1894, pág. 10.

${ }^{44}$ Neues Wiener Journal, 28 de diciembre de 1897, pág. 4.

45 "Are of Noble Blood. Some Characters Better Known than Respected”, Denver Evening Post, 5 de junio de 1895 , pág. 6.

${ }^{46}$ Le Gaulois, 16 de noviembre de 1909, pág. 2; Journal des Débats, 17 de noviembre de 1909, pág. 3.

${ }^{47}$ Serge Basset, "Au cimetière des chiens", Le Figaro, 9 de octubre de 1900, págs. 1-2.

${ }^{48}$ Berthe Vercler, "Le Cimetière pour chiens“, La Revue contemporaine, 25 de octubre de 1900, págs. 15-18, aquí pág. 18.

${ }^{49}$ Chamfort, "L’ami de 1'homme », Le Matin, 18 de noviembre de 1900, pág. 5.
} 
cual se ha colocado una corona de príncipe y que fue erigido por iniciativa de la princesa de Cerchiara Pignatelli" ${ }^{50}$. En 1902, le toca el turno a Rubén Darío, quien concluye una crónica bastante amplia con esta observación:

Al salir, me llamó la atención un monumento sobre el cual se alza una corona heráldica. Es el de una perra de la princesa Cerchiara Pignatelli. La dedicatoria explica una vida de sufrimiento, mitigada por la compañía del fiel animal, y ve uno cómo se juntan en los mismos simples afectos, las sensibles porteras y las aristocráticas damas $^{51}$.

Ignoramos de qué manera la perra Emma (un lebrel) salvó la vida a su dueña Gaëtana Pignatelli, pero parece que en la vida de las dos hermanas enemigas los "toutous fidèles", como los llamaban a veces, cumplieron un papel importante. Cuentan que Emmanuela tenía la costumbre de ensayar sus collares de perlas en el cuello de uno de sus perros antes de ponérselos ella misma (Leibenson: 149) y que hacía dormir a sus perros ante la puerta de su cuarto para impedir el acceso a quien sea, incluyendo a su marido ${ }^{52}$. En el célebre cuadro de Jean Béraud, El salón de la condesa Potocka $(1887)^{53}$, el centro de la imagen es ocupado por un magnífico lebrel; pero en realidad fueron unos cinco animales los que solían animar el salón de la condesa (Leibenson: 286). Durante la última etapa de su matrimonio con el conde Potocki, cuando tuvo que reducir dramáticamente su famoso salón y trasladarse a vivir en Auteil (considerado en aquel tiempo "en provincia"), Emmanuela se aislaba cada vez más y no soportaba ya otra compañía que la de sus perros (Leibenson: 281), dejó a dieciocho de ellos abandonados en una perrera, mientras otros mordieron a un obrero y a un policía (Leibenson: 406). La que siempre "mostraba un desprecio a la humanidad digna de una filósofa cínica... se descuida, se deja engordar, ya no se ocupa de otra cosa que de sus perros", dice Proust ${ }^{54}$. No duerme, pasa la noche cuidando a una perra enferma, y "a veces, en el corazón del Bosque de Bolonia, en una avenida alejada, en las brumas de la madrugada", se la ve "seguida y precedida de una jauría aullante" Leibenson concluye su biografía de Emmanuela con un capítulo que se lama "El síndrome de Noé" 56 , donde además de las hermanas Pignatelli habla de otras personajes públicos como Rose Catana y Gladys Deacon. Con esta última estamos volviendo al mundo de Rubén Darío, ya que el poeta habla de ella en una crónica escrita en septiembre de $1901 .{ }^{57}$ Pero parece que Deacon, convertida en duquesa de Marlborough en 1921 -la que inspiró a Proust la reflexión "no he visto nunca una muchacha tan bella, ni de una tan magnífica inteligencia, de un carácter tan bueno y delicioso" Painter: 87)- no desarrolló el síndrome sino hasta bastante tarde, en la última etapa de su vida.

Darío, lector asiduo del Figaro, conocía obviamente el citado artículo de Proust; pero nosotros estamos buscando las huellas de Gaëtana, que se ha quedado en silencio después de enterrar a su perra. Darío, en sus crónicas dedicadas explícitamente a los "faits divers", donde anuncia "hechos, cosas y hombres" 58 , o "Hombres, hechos e ideas" ${ }^{2}$, y donde no desdeña hablar de "desastres, asesinatos, raptos, agresiones, accidentes, robos, extravagancias" (Barthes: 260-261), bien pudo haberla mencionado. Según Barthes, uno de los tipos de relación que pueden articular la estructura del "fait divers" es la relación de coincidencia, y entre ellas "la que aproxima dos términos (dos contenidos) cualitativamente distantes: una mujer pone en fuga a cuatro gángsters, un juez desaparece en Pigalle, unos pescadores islandeses pescan una vaca (una princesa canta en un café concierto). Hay una especie de distancia lógica entre la debilidad de la mujer y el número de los gángsters, la magistratura y Pigalle, la pesca y la vaca (la princesa y el café concierto), y el fait divers se pone repentinamente a suprimir esta distancia. ... nos acercamos aquí a una figura retórica

\footnotetext{
50 "Der Hundefriedhof in Paris", Illustrirtres Wiener Extrablatt, 2 de agosto de 1901, pág. 17.

${ }^{51}$ Rubén Darío, “El cementerio de los perros.” La Nación. Suplemento, 11 de octubre de 1902; Darío 1907: $258-259$.

${ }^{52}$ Leibenson 219, 295.

${ }^{53}$ El cuadro representa el grupo de los "Macabeos", entre ellos los pintores Édouard Detaille y Henri Gervex, el historiador Gustave Schlumberger, el funcionario Xavier Charmes, el filósofo Elme-Marie Caro y el mismo Béraud, todos ellos reunidos bajo la mirada de Emmanuela y su retrato por Bonnat.

${ }^{54}$ Horatio (= Marcel Proust), "Le Salon de la Comtesse Potocka“, Le Figaro, 13 de mayo de 1904, pág. 3.

${ }^{55}$ Ibíd.

${ }^{56}$ El nombre oficial de ese síndrome es "trastorno por acumulación de animales".

57 "Los amores del Kronprinz", La Nación. Suplemento Semanal Ilustrado, 23 de octubre de 1902. En Parisiana con el título "Idilio en falso" (Darío 1907: $67-73$.

${ }^{58}$ Crónica sin título, fechada en Buenos Aires el 1 de noviembre de 1898, El Orden (Tucumán), 3 de noviembre de 1898.

${ }^{59}$ Serie de crónicas escritas en París y publicadas en La Nación en los años 1901-1902.
} 
fundamental en el discurso de nuestra civilización: la antítesis. ... toda oposición pertenece a un mundo deliberadamente construido: un dios vaga detrás del suceso" (Barthes: 267-270).

Que Darío no haya mencionado a Gaëtana en otras crónicas se explica en parte por un desfase cronológico: la princesa ocupó los titulares durante los años 1883-1890, y la actividad periodística intensa de Darío comienza en 1892, a pesar de todo lo que publicó anteriormente en los periódicos centroamericanos y chilenos. Mientras no se descubran fuentes nuevas, tenemos que suponer que la fórmula "una vida de sufrimiento" que usa en Parisiana le fue inspirada por la mera lectura de la inscripción en la tumba. La dedicatoria del monumento a "mi fiel compañera y única amiga de mi vida errante y desolada" es suficientemente explícita como expresión de una persona llegada a la última etapa de la desilusión y del desprecio a la humanidad, candidata a las estadísticas de Durkheim, aunque, de acuerdo a este investigador, "el suicidio es una manifestación esencialmente masculina. A una mujer que se mata corresponden en promedio 4 hombres que se suicidan" (Durkheim: 39). Pero nuestro poeta no conocía los detalles de la vida de Gaëtana Pignatelli y podríamos decir que no sabe hasta qué punto estaba en lo cierto.

\section{Referencias bibliográficas}

Anónimo (1883). The Pretty Women of Paris: Their Names and Addresses, Qualities and Faults, Being a Complete Directory or Guide to Pleasure for Visitors to the Gay City. Impresión privada.

Barbey D'Aurevilly, Jules (1874). Les Diaboliques. Paris: E. Dentu.

Barthes, Roland (2003). Ensayos críticos. Traducción de francés por Carlos Pujol. Buenos Aires: Seix Barral.

Benjamin, Walter (1966). Angelus Novus. Ausgewählte Schriften 2. Frankfurt am Main: Suhrkamp.

Darío, Rubén (1907). Parisiana. Madrid: Fernando Fé. Modernistas.

(1997). Prosas profanas y otros poemas. Edc. de Ricardo Llopesa. Valencia: Instituto de Estudios

---, ----- (2015). Los Raros. Edc. de Günther Schmigalle. Estudio prel. de Jorge Eduardo Arellano. Berlin: Edition Tranvía-Verlag Walter Frey.

Durkheim, Émile (1897). Le Suicide, étude de sociologie. Paris: Alcan.

Leibeson, Claude (2016). La comtesse Potocka. Une égérie de la Belle Époque. Paris: Lacurne.

Painter, George D. (1966). Marcel Proust. II. Les années de maturité (1904-1922. Paris: Mercure de France.

Pignatelli, Maria Gaëtana (1889). Die Beichte meines Lebens. Berlin: Hermann Schmidt.

Said, Edward (2004). Humanism and Democratic Criticism. New York: Columbia University Press.

Zamoyski, Jean (1886). Mémoire ... au sujet de la demande en cassation de mariage présentée à Rome et de la demande en divorce, introduite à Paris par sa femme, Louise-Eugénie-Sophie-Elisabeth Pélissier de Malakoff, fille de Amable Pélissier, duc de Malakoff, maréchal de France, et de Sophie, marquise de Paniega. Vienne: Imprimerie de C. H. Reisser und M. Werthner. 